Strahlenther Onkol 2012 · 188:847-847

DOI 10.1007/s00066-012-0198-9

Online publiziert: 11. August 2012

๑) Springer-Verlag 2012

\title{
H. Sack
}

Essen

\section{Professor Dr. Hans-Bruno Makoski zur Vollendung des 70. Lebensjahres}

tumoren, die Radiochemotherapie, die arteriovenösen Malformationen im Gehirn und die Radiosynoviorthesen rheumatischer Gelenkerkrankungen. Seine Habilitation erhielt er an der Essener Fakultät am 29. Januar 1980.

Schon am 1. Juli 1977 übernahm Herr Makoski bereits vor der offiziellen Inbetriebnahme die Klinik für Strahlenheilkunde, Radioonkologie und Nuklearmedizin an den Städtischen Kliniken Duisburg. Auch hier hat er, dank seiner umfassenden medizinischen Kenntnisse und dank der guten Kooperation im Klinikum und mit den Ärzten in der näheren und weiteren Umgebung, die Abteilung zu einer der Führenden aufgebaut. Seine Patienten verdanken ihm viel und verehrten ihn sehr. Er selbst und seine Mitarbeiter genossen einen hervorragenden Ruf, die Klinik war stets auf dem aktuellen technischen Stand. Seinem hohen Ansehen verdankte er die Wahl zum Ärztlichen Direktor des Duisburger Klinikums 1991 bis 1994 und 2007 bis 2010.

Für die DEGRO richtete Hans-Bruno Makoski die Jahrestagung 2003 in Essen aus, die vielen noch in bester Erinnerung geblieben ist. Er ist Mitglied zahlreicher nationaler und internationaler Gesellschaften und war über viele Jahre im wissenschaftlichen Beirat der Strahlentherapie und Onkologie tätig.

Zum Schluss soll die vierte wichtige Berufung im Leben von Hans-Bruno nicht vergessen werden. Es sind seine Ehe mit Roswitha seit 1967, seine Familie mit den erfolgreichen Söhnen Roman und Kyrill und seine inzwischen große Familie mit den Schwiegertöchtern und Enkeln. Die Möglichkeit der Entspannung zu Hause bei seiner Gattin und in der Familie gehö- ren hier in erster Linie genannt. Das Rennradfahren, allein, mit seinen Söhnen und im Verein, hat er semiprofessionell betrieben.Er musste es aufgeben, weil die körperlichen Belastungen zu einer schweren Erkrankung führten, die er dank seiner Energie vollständig überwinden konnte. Wir, seine Freunde und Kollegen aus dem Berufsverband und aus der DEGRO, kennen und schätzen ihn dank seiner in sich ruhenden Persönlichkeit, seiner stets auf Ausgleich bemühten Haltung und der Treue zu seinen Freunden. Wir freuen uns, ihn auch im Ruhestand häufig zu sehen und zu erleben. „Ad multos annos!“

Horst Sack

\section{Korrespondenzadresse}

Prof. Dr. H. Sack

Wolfsbachweg 29, 45133 Essen

horst.sack@t-online.de

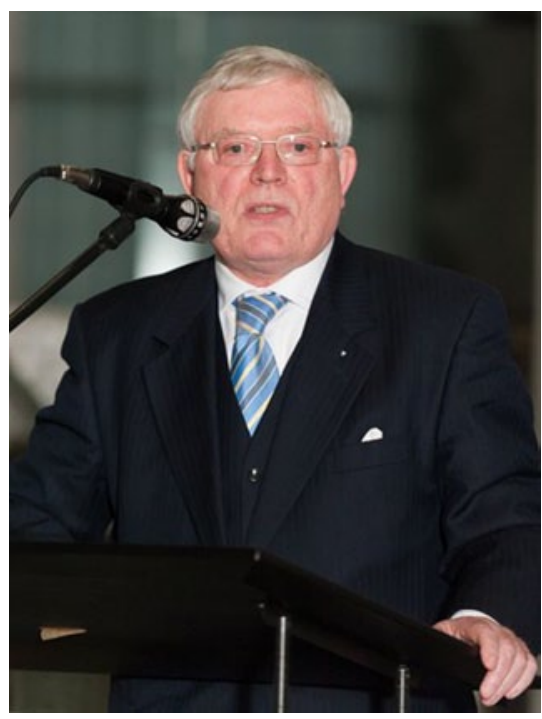

Abb. 1 \ Prof. Dr. Hans-Bruno Makoski 